\title{
Effect of Inuline and Oatmeal Addition on Fat and Dietary Fiber Content in Hot Press Wheat Flour Tortilla
}

\author{
Erick Heredia-Olea ${ }^{2}$, Alejandra Martínez-Martínez ${ }^{1}$, Sylvia Payan-Tamez ${ }^{1}$, Isabel Palomera-Santandreu ${ }^{1}$, \\ Sara Guajardo-Flores ${ }^{1} \&$ Esther Pérez-Carrillo ${ }^{2}$ \\ 1 Departamento de Biotecnología y Alimentos, Escuela de Biotecnología y Alimentos, Tecnológico de \\ Monterrey, Av. Eugenio Garza Sada 2501 Sur, CP 64849, Monterrey, N.L., Mexico \\ ${ }^{2}$ Centro de Biotecnología-FEMSA, Escuela de Ciencias e Ingenieria, Tecnológico de Monterrey, Av. Eugenio \\ Garza Sada 2501 Sur, CP 64849, Monterrey, N.L., Mexico \\ Correspondence: Esther Pérez-Carrillo, Escuela de Ciencias e Ingeniería, Tecnológico de Monterrey, Monterrey, \\ Nuevo León, México. Tel: 52-818-358-2000. E-mail: perez.carrillo@itesm.mx
}

Received: September 29, 2014 Accepted: December 5, $2014 \quad$ Online Published: December 19, 2014

doi:10.5539/jfr.v4n2p44 URL: http://dx.doi.org/10.5539/jfr.v4n2p44

\begin{abstract}
Reduced fat wheat tortilla was formulated A formulation reduced in shortening with the fiber dietary properties of the whole grain has been proposed. The aim of this research was to evaluate the effect of the replacement of wheat flour by oatmeal and shortening by inuline, on some physical characteristics and fat and dietary content of wheat tortillas. Three treatments of tortilla were tested: refined, whole and a 4:3:3 refined: whole flour: oatmeal plus 9:1 shortening: inuline. Analysis of dietary fiber, fat, texture, diameter, thickness and color were performed. Results showed that this oatmeal-inuline tortillas had similar texture and thickness and lower diameter that conventional wheat tortillas. Oatmeal-inuline tortillas are redder than refined wheat tortilla. Oatmeal-inuline substitution tortilla had $45 \%$ less fat and $71 \%$ more dietary fiber than refined flour tortilla with same textural characteristics.
\end{abstract}

Keywords: wheat tortillas, dietary fiber, oatmeal, inuline, fat reduction

\section{Introduction}

Observational and intervention studies have shown that several chronic diseases can be prevented by lifestyle measures, including changes in diet composition. For this reason the relationship between food and health has an increasing impact on food innovation due to the popularity of the concept of functional food. The practice of using nutrition knowledge at food product level to improve the health of the consumer forms the general concept for functional foods. In recent years, dietary fiber (DF) has received increasing attention from researchers and food industry due to the likely beneficial effects on the reduction of coronary heart-related diseases, diabetes incidence and gut neoplasia (Peressini \& Sensidoni, 2009). $\beta$-D-glucan, present in oats and barley, has demonstrated to be effective in attenuating postprandial glycaemic and insulin responses. However, the natural content of $\beta$-glucan in normal oats and barley is insufficient to lower metabolic responses to bread. In fact, it has been shown that the consumption of wholemeal products made with common cultivars of oat or barley, such as wholemeal barley bread or oat muesli and oat porridge, did not result in lower postprandial blood glucose or insulin responses in healthy subjects compared with white bread (Scanizza et al., 2013). Fiber-rich foods are produced by adding functional fiber or using basic ingredients with high-DF content, e.g. wholemeal bread, fiber-rich oat bread In particular, fiber-rich breads are characterized by reduced volume, compacted crumb compared to traditional bread. Consequently, there is much interest in the development of white bread with elevated DF (Peressini \& Sensidoni, 2009; Mis et al., 2012). The physicochemical characteristics can be used to differentiate various types of fibers. Based on their simulated intestinal solubility, dietary fibers are classified as either insoluble or soluble. Into soluble fiber group are inuline, inuline-type fructans and linear polidisperse carbohydrate material consisting mainly of D-fructose. Recent studies have identified several beneficial attributes of oligofructose and inuline. They included stimulation of colonic bifidobacteria and lactobacilli, improvement of bowel function, increased calcium absorption, positive effects on glucose and lipid metabolism, and stimulation of immune system (Peressini \& Sensidoni, 2009).

Wheat tortillas were originated in North Mexico but have emerged from an ethnic specialty item to a main-stream bread widely consumed in the United States and increasing in other parts of the world. Tortillas 
provide a compact, convenient, and efficient way to hold a variety of foods and are thus very well suited for the "on the go" lifestyle that characterizes much of the world today. The key quality attributes that provide the desired functionality in tortillas are extensibility during pressing (diameter) and retention of flexibility over time (shelf stability) (Alviola \& Awika, 2010). Important works has been developed to improve aminoacids profile, glycemic index, antioxidant profile, dietary fiber content (Friend, 1992; Scazzina et al., 2008; Barros et al., 2010; Anton et al., 2008; Prasopsunwattana et al., 2009), despite the large amount of information available on the nutritional and physiological properties of fructans, there is not information available on their effects on wheat flour tortilla quality. O'Brien (2003) observed that fat could be substituted in bread until $25 \%$ without effect on quality characteristics.

The aim of this research was to evaluate the effect of the partial substitution of wheat flour and vegetal shortening by oatmeal and inuline, respectively on texture, dimensions, color, crude fat and dietary fiber of hot-press wheat tortillas.

\section{Materials and Methods}

\subsection{Tortilla Formulation}

Commercial refined wheat flour and oatmeal flour were used for tortilla preparation. Gluten and sedimentation of the flour samples were determined using the AACC Methods 38-10 and 50-60 respectively (AACC, 2000). The basic formulation included $200 \mathrm{~g}$ refined wheat flour $14 \%$ moisture basis $(\mathrm{mb}), 30 \mathrm{~g}$ vegetable shortening (Productos Lirio, Monterrey, NL, Mexico), $3 \mathrm{~g}$ refined iodized salt (La Fina, Sales del Istmo, Coatzacoalcos, Ver., Mexico), $4.0 \mathrm{~g}$ double acting baking powder (Rexal, Productos Mexicanos, Monterrey, NL, Mexico), $2 \mathrm{~g}$ lowfat dry milk (Dairy American, Hegart,México), 0.4 g Citrogen (TECSA, Monterrey, NL, Mexico), and distilled water. In case of whole wheat tortilla formulation refined flour was changed by whole wheat flour $200 \mathrm{~g}$ $(14 \% \mathrm{mb})$. In the oat-wheat flour tortilla formulation, flour was replaced by a proportion 4:3:3 of refined, whole grain and oatmeal flour, and also shortening was replaced by inuline at a proportion 9:1.

\subsection{Preliminary Tortilla Trials}

Tortillas were processed following the hot-press procedure in which optimally developed dough were hot-pressed into discs and baked. Tortillas were prepared by methods delineated by Posner et al. (2014) with slight modifications. $200 \mathrm{~g}$ flour $(14 \% \mathrm{mb})$ plus ingredients listed above were mixed with a predetermined volume of warm water $\left(40{ }^{\circ} \mathrm{C}\right)$ in a $100-200 \mathrm{~g}$ dough mixer (National Manufacturing Co., Lincoln, NE). Optimum water absorption and mix times were subjectively determined by observing dough handling properties. Dough texture was subjectively evaluated using a 1 to 5 rating. A subjective score of 1 meant that dough was slack or soft and needed less force to extend whereas a score of 5 was assigned to very rough or firm dough that needed high force to extend. Water absorption was varied in order to obtain a dough with intermediate properties ( 2.5 in the subjective score of 1 to 5) suited for hot-press tortillas. Experimental doughs were divided into $30 \pm$ $0.25 \mathrm{~g}$ pieces, mechanically rounded and allowed to rest in a proof cabinet (National Manufacturing Co., Lincoln, $\mathrm{NE}$ ) adjusted to $29^{\circ} \mathrm{C}$ and $85 \% \mathrm{RH}$ for $30 \mathrm{~min}$. Each dough ball was flattened using a commercial inclined hot pressed for $3.13 \mathrm{sec}$. The temperature of the hot plates was adjusted at $187 \pm 5^{\circ} \mathrm{C}$ and the gap between the hot plates adjusted to $1.75 \mathrm{~mm}$. The resulting flattened tortilla discs were baked on a four-pass circular moving griddle set at different temperatures (Manufacturas C\&D Industriales, Monterrey, NL, Mexico). The raw tortilla was baked on one side for $10.79 \mathrm{sec}$ at $200 \pm 5{ }^{\circ} \mathrm{C}$, turned over and baked for another $11.01 \mathrm{~s}$ at $260 \pm 5{ }^{\circ} \mathrm{C}$, turned over again and baked for $11.04 \mathrm{~s}$ at $265 \pm 5^{\circ} \mathrm{C}$ and finally turned over again and baked at $230 \pm 5^{\circ} \mathrm{C}$ for $13.60 \mathrm{~s}$ (Serna Saldivar, 2012). At the end of these trials, the optimum water absorptions for the pilot plant studies were determined.

\subsection{Pilot Plant Tortilla Trials}

Tortilla trials consisted of mixing $2 \mathrm{~kg}$ of flour $(14 \% \mathrm{mb})$ with the ingredients listed above and optimum water absorption determined by the preliminary tortilla trials. The dough mixing protocol consisted of first blending dry ingredients with the shortening at slow speed with a hook attachment for $4 \mathrm{~min}$. Then, distilled water has been tempered to $40{ }^{\circ} \mathrm{C}$ was added and blend mixed at slow speed for $1 \mathrm{~min}$ and then has changed at medium speed. $30 \mathrm{~g}$ pieces and rounded manually and immediately placed in the proof cabinet set at $29^{\circ} \mathrm{C}$ and $85 \% \mathrm{RH}$ for $30 \mathrm{~min}$. Then, the relaxed dough balls were hot-pressed into tortilla discs and baked as explained above. The baked tortillas were cooled on a wire rack to room temperature $\left(25 \pm 2{ }^{\circ} \mathrm{C}\right)$ for about $30 \mathrm{~min}$, placed inside sealed polyethylene bags and kept at room temperature for further evaluations (Serna Saldivar, 2012). 


\subsection{Evaluation of Tortilla Properties}

Ten tortillas from each treatment were randomly selected and measured for diameter and thickness. The diameter of tortillas was the average of two diagonal measurements. Tortilla dietary fiber (soluble and insoluble), was determined using the commercial kit of Megazyme (AACC approved method 32-45.01, and 32-50.01). Crude fat was evaluated according to approved AOAC method 30-20.Two tortillas from each batch were randomly selected and measured for color using the Minolta chromameter (model CR-300, Minolta Camera Co., Ltd., Chuo-Ku, Osaka, Japan). Values for $\mathrm{L}^{*}$ (brightness or whiteness), $\mathrm{a}^{*}$ (redness and greenness), and $\mathrm{b}^{*}$ (yellowness and blueness) were measured. Surface color was measured from four different randomly selected spots of each tortilla. At day 0,1 , and 5 of storage, texture analysis were conducted using a TA.XT2i Texture Analyzer (Stable Micro Systems, Godalming, England) according to Posner et al. (2014).

\subsection{Sensory Evaluation}

Thirty-two untrained panelists evaluated the overall acceptability of tortillas. Testing was conducted with refined wheat, whole wheat and oat-whole wheat tortillas. Each panelist was simultaneously given six coded samples along with a ballot, and was asked to rate each sensory attribute. Tortillas were evaluated for texture, flavor overall quality on a 5-point hedonic scale (Serna Saldivar, 2012).

\subsection{Statistical Analysis}

Flour characteristics and tortilla data were analyzed using a randomized experimental design using analysis of variance. Tortilla texture measurements were analyzed with non-parametric tests (Kruskal Wallis). Minimum significant differences and Duncan's tests were applied to determine differences among means $(\mathrm{P}<0.05)$. Flour characteristics and tortilla data were analyzed using a randomized experimental design using analysis of variance. Tortilla texture and sensory evaluation measurements were analyzed with non-parametric tests (Kruskal Wallis). Minimum significant differences and Duncan's tests were applied to determine differences among means $(\mathrm{P}<0.05)$.

\section{Results and Discussion}

\subsection{Preliminary Tortilla Trials}

Oatmeal flour substitution reduced wet gluten content and sedimentation with respect a RF flour (Table 1). Sedimentation value was lower too, less the half that their counterpart refined wheat flour. Table 1 summarizes results of the preliminary tortilla trials. Flours $(14 \% \mathrm{mb})$ were tested using three different water absorptions and optimum mix times and dough consistency evaluated. Whole wheat flour and oat-wheat had higher water absorption compared with the control to produce optimum dough. Fiber-rich preparations are known for their ability to absorb considerable amounts of water.

Table 1. Gluten and sedimentation flour data and micromixing tests of refined wheat, whole wheat and oat-whole wheat flours for tortilla production ${ }^{\mathrm{a}}$

\begin{tabular}{|c|c|c|c|c|c|c|c|}
\hline \multirow{2}{*}{ Treatment } & \multicolumn{2}{|c|}{ Gluten (\%) } & \multirow{2}{*}{ Sedimentation } & \multirow{2}{*}{ Water Absorption, \% } & \multirow{2}{*}{$\begin{array}{c}\text { Optimum Mix } \\
\text { Time (min) }\end{array}$} & \multirow{2}{*}{$\begin{array}{l}\text { Subjective } \\
\text { Dough } \\
\text { Consistency }^{\mathrm{b}}\end{array}$} & \multirow{2}{*}{$\begin{array}{l}\text { Optimum Water } \\
\text { Absorption }{ }^{\mathrm{c}}, \%\end{array}$} \\
\hline & Wet & Dry & & & & & \\
\hline \multirow{3}{*}{$\begin{array}{c}\text { Refined } \\
\text { Wheat Flour }\end{array}$} & \multirow{3}{*}{41.77} & \multirow{3}{*}{11.7} & \multirow{3}{*}{23.36} & 50 & 5 & 3 & \multirow{3}{*}{50} \\
\hline & & & & 51 & 6 & 2 & \\
\hline & & & & 54 & 7 & 1 & \\
\hline \multirow{3}{*}{$\begin{array}{c}\text { Whole } \\
\text { Wheat Flour }\end{array}$} & \multirow{3}{*}{37.78} & \multirow{3}{*}{10.7} & \multirow{3}{*}{18.43} & 53 & 5 & 5 & \multirow{3}{*}{54} \\
\hline & & & & 54 & 5 & 3 & \\
\hline & & & & 55 & 6 & 2 & \\
\hline \multirow{3}{*}{$\begin{array}{l}\text { Oat-Whole } \\
\text { Wheat Flour }\end{array}$} & \multirow{3}{*}{27.21} & \multirow{3}{*}{9.26} & \multirow{3}{*}{16.64} & 53 & 5 & 4 & \multirow{3}{*}{54} \\
\hline & & & & 54 & 5 & 3 & \\
\hline & & & & 55 & 6 & 2 & \\
\hline
\end{tabular}

${ }^{\mathrm{a}}$ Each value is the average of at least three observations. Data on $14 \%$ moisture basis flour.

${ }^{\mathrm{b}}$ Subjectively determined using a 1 to 5 scale where 5 meant that dough was extremely firm and 1 extremely slack. The optimum consistency was rated as 3 . 


\subsection{Pilot Plant Tortilla Trials}

Table 2 summarizes results of the pilot plant hot-press tortilla trials performed at optimum water absorptions shown in Table 1. All types of tortillas weighed approximately $26 \mathrm{~g}$. Refined wheat flour tortillas had the highest diameter $(14.61 \pm 0.56 \mathrm{~cm})$. All treatments had the same thicknesses after tortilla baking $1.0 \pm 0.35 \mathrm{~mm}$. Tortilla $\mathrm{L}^{*}$ value test is the objective method currently used to support the subjective opacity test. Interestingly, there were not differences $(\mathrm{P} \leq 0.05)$ among the refined wheat flour tortillas and oat-wheat flour tortillas in $\mathrm{L}^{*}$ and $\mathrm{b}^{*}$ values for color parameters. However, the highest $\mathrm{a}^{*}$ value was achieved for whole wheat flour tortilla. Oat-wheat tortillas had the lowest crude fat percentage. In the other hand, the highest soluble dietary fiber was reported for oat-whole wheat flour and the highest insoluble dietary fiber was reported for whole wheat flour.

Table 2. Weight, diameter, thickness, and color of commercial hot-press tortillas made with refined wheat, whole wheat and oat-whole wheat flours ${ }^{\mathrm{a}}$

\begin{tabular}{|c|c|c|c|}
\hline Parameter & Refined Wheat Flour & Whole Wheat Flour & Oat Whole Wheat Flour \\
\hline Weight (g) & $26.17 \pm 0.54 \mathrm{a}$ & $25.50 \pm 0.66 \mathrm{a}$ & $24.15 \pm 0.17 \mathrm{a}$ \\
\hline Diameter (cm) & $14.61 \pm 0.56 \mathrm{a}$ & $13.69 \pm 0.55 b$ & $13.54 \pm 0.17 \mathrm{~b}$ \\
\hline Thickness (mm) & $1.02 \pm 0.90 \mathrm{a}$ & $0.93 \pm 0.25 \mathrm{a}$ & $0.97 \pm 0.25 \mathrm{a}$ \\
\hline \multicolumn{4}{|l|}{ Color Parameter } \\
\hline $\mathrm{L}^{*}$ & $73.77 \pm 6.25 \mathrm{a}$ & $56.85 \pm 2.21 b$ & $71.08 \pm 0.66 \mathrm{a}$ \\
\hline $\mathrm{a}^{*}$ & $-0.80 \pm 0.5 \mathrm{a}$ & $6.83 \pm 0.66 \mathrm{c}$ & $2.72 \pm 0.31 b$ \\
\hline$b^{*}$ & $16.52 \pm 1.75 \mathrm{a}$ & $19.40 \pm 1.16 \mathrm{a}$ & $16.89 \pm 1.54 \mathrm{a}$ \\
\hline Crude Fat & $8.94 a$ & $8.08 \mathrm{~b}$ & $6.18 \mathrm{c}$ \\
\hline \multicolumn{4}{|l|}{ Dieatary Fiber $(\mathrm{g} / 100 \mathrm{~g})$} \\
\hline Soluble & $3.06 \pm 0.09 b$ & $2.89 \pm 0.07 b$ & $3.47 \pm 0.57 \mathrm{a}$ \\
\hline Insoluble & $2.35 \pm 0.14 \mathrm{c}$ & $10.63 \pm 0.26 \mathrm{a}$ & $5.79 \pm 0.14 \mathrm{~b}$ \\
\hline
\end{tabular}

${ }^{a}$ Each value is the average of at least three observations. Means with different letter(s) in each column are statistically different $(\mathrm{P}<0.05)$.

\subsection{Tortilla Texture}

The textural shelf life of tortillas plays a critical role in terms of quality and acceptance. The fresh tortillas (day 0 ) had the lowest force and largest extension values (Table 3). Regular wheat flour tortillas had the best texture at day 0 . However, in case of regular wheat flour tortilla, most of the loss of texture in all the tortillas occurred throughout the first day of storage. Oat-whole wheat flour tortilla had the same force value that whole wheat tortilla at day 0 Interestingly, oat-wheat flour tortilla had a lower increasing in force value than whole wheat tortilla, even that this was a low shortening formula. The force values related to tortilla firmness almost doubled after $24 \mathrm{~h}$ of storage. Likewise, the tortilla extension values after one day of storage were between one half to one third of the originally values observed in fresh tortillas. The higher force and lower extension values are typically observed in bakery products and are mainly attributed to starch retrogradation. A comparison of the 5-day stored tortillas indicated that oat-wheat tortilla had better textural properties than whole wheat tortillas. 
Table 3. Effect of type of flour and storage for 5 days at room temperature on the textural properties of hot press tortillas made with refined wheat, whole wheat and oat-whole wheat flours ${ }^{\mathrm{a}}$

\begin{tabular}{llll}
\hline & Refined Wheat Flour & Whole Wheat Flour & Oat Whole Wheat Flour \\
\hline Force $(\mathrm{N})$ & & & \\
Day 0 & $0.07 \pm 0.11$ & $0.21 \pm 0.18$ & $0.19 \pm 0.13$ \\
Day 1 & $0.17 \pm 0.15$ & $0.24 \pm 0.11$ & $0.22 \pm 0.14$ \\
Day 5 & $0.23 \pm 0.00$ & $0.27 \pm 0.03$ & $0.23 \pm 0.06$ \\
Extension (mm) & & & \\
Day 0 & $11.14 \pm 2.31$ & $9.279 \pm 2.00$ & $10.75 \pm 0.78$ \\
Day 1 & $10.64 \pm 1.53$ & $6.03 \pm 0.50$ & $11.38 \pm 2.12$ \\
Day 5 & $8.23 \pm 0.311$ & $4.00 \pm 1.20$ & $4.87 \pm 1.33$ \\
\hline
\end{tabular}

\subsection{Tortilla Sensorial Test}

Consumer acceptability scores (Table 4) indicated that all tortillas like ranged in the same value. Highest acceptability was for refined wheat flour followed by oat-whole wheat flour. The lowest acceptability was reported for whole wheat tortillas.

Table 4. Sensorial parameters of commercial hot-press tortillas made with refined wheat flour, whole wheat flour or oat-whole wheat flour ${ }^{1}$

\begin{tabular}{llll}
\hline Parameter & $\begin{array}{l}\text { Treatment } \\
\text { Refined Wheat Flour }\end{array}$ & Whole Wheat Flour & Oat-Whole Wheat Flour \\
\hline Texture & 2 & 2 & 2 \\
Flavor & 2 & 2 & 2 \\
Overall quality & 2 & 2 & 2 \\
Acceptance (\%) & 40.0 & 23.3 & 36.7
\end{tabular}

${ }^{1}$ Each value is the mode of at least thirty observation: $1=$ like very much, $2=$ like, $3=$ neither like nor dislike, 4 $=$ dislike, $5=$ dislike very much.

\section{Discussion}

\subsection{Preliminary Tortilla Trials}

Typically oat addition affected dough negatively, however, oat-inuline interaction gave good tortilla dough. Wet and dry gluten and sedimentation values (Table 1) of refined wheat flour (RW) and whole wheat flour (WW) are similar to reported by Zhao et al. (2010) and Barros et al. (2010a). This attribute is mainly determined by the presence, in fiber structure, of a large number of hydroxyl groups which enter into interactions with water via hydrogen bonds (Mis et al., 2012). Barros et al. (2010) reported that whole wheat flours had a higher water absorption and a longer mixing time than their refined flour counterparts. It took longer and more water for whole wheat flour to hydrate and develop gluten because the proteins had to compete for water with fiber (Barros et al., 2010). Peressini and Sensidoni (2009) observed that inuline addition to wheat flour increased mixing stability. The addition of inuline improved the strength of the doughs and could be used to replace a portion of wheat flour without causing detrimental consequences for dough quality (Peressini \& Sensidoni, 2009).

\subsection{Pilot Plant Tortilla Trials}

Barros et al. (2010) reported highest b* values. Will, Alviola and Awika (2010) and Anton et al. (2008) reported similar color parameters for refined wheat tortilla. Prasopsunwattana et al. (2009) reported for a low-fat low-cab commercial wheat tortilla values is one percentage unit lower than reported in this work (Table 2). In the other hand, the most common form of dietary fiber is insoluble fiber (cellulose, lignin and some hemicellulose), which reduces constipation and is being studied for its potential to reduce the risk of colon/rectal. Although soluble 
fiber is less common in foods than insoluble fiber, it is believed to have important effects in the digestive and absorptive processes (Dreher, 2001). Friend et al. (1992) reported similar fiber values in whole wheat tortilla. However, oat-wheat tortillas had the highest soluble dietary fiber percentage (Table 2). Prasopsunwattana et al. (2009) reported similar soluble dietary fiber values for wheat tortillas supplemented with barley. Soluble fiber is partially but entirely water-soluble, and includes pectin, guar gum and glucomannan psyllium, $\beta$-glucan and arabinoxylans. Soluble dietary fiber promotes beneficial physiological effects. Several studies conducted during the last decade have shown that viscous soluble fiber plays an important role in controlling postprandial glycemic and insulin responses because of its effects on macronutrients absorption from the gut. Dietary fiber intake should range from 20 to $35 \mathrm{~g}$ /day (Peressini et al., 2009), with 2 tortillas consumer cover $25 \%$ of this requirement to be complemented with other kind of foods.

\subsection{Tortilla Texture}

Prasopsunwattana et al. (2009) reported important effect of barley addition and low-fat:low-cab:high-fiber tortillas even this have less fat and more dietary fiber and affected sensorial perception. Most flour tortillas are expected to last on the shelf at room temperature for at least one week and up to three weeks. Staling of flour tortillas is mainly due to the gradual transformation of amorphous starch to a partially crystalline retrograded state. The texture of tortillas is affected by the gluten, amount and types of baking powder (Adams \& Waniska, 2002), shortening and processing parameters such as time-temperature during the critical baking operation. It is probably that inuline acts as a replacement of shortening in the oat-wheat tortilla and gives body, texture, consistency and viscosity to it. Inuline also improves the acceptability of food products because it acts as a thickening agent, stabilizer and retains water providing moisture (O’Brien et al., 2003; Madrigal et al., 2007). However, inuline-oatmeal interaction could be present. Seetherman et al. (1997) observed that soluble and insoluble fibres influenced both the quality and microstructure of dough and wheat flour tortillas. Doughs containing $8 \%$ soluble fibre had poor gluten development and extensive starch gelatinization during baking. This resulted in a tortilla with a dense, pasty crumb. Doughs containing $8 \%$ insoluble fibre had better gluten structures than those prepared using soluble fibres. Strands of insoluble fibre particles, however, physically disrupted the gluten network, causing the air bubbles to collapse, and decreased the shelf-stability of tortillas. It appears that soluble and insoluble fibres weaken the gluten matrix by different mechanisms (Seetheraman et al., 1997). Previously works (Wang et al., 2002) with inuline added to bread showed not effect on textural profile analysis however volume was decreased. In case of tortilla volume is not relevant parameter. This make tortilla an excellent way to improve inuline consumption because volume is not too important like in bread.

\subsection{Tortilla Sensorial Test}

The higher acceptance of refined wheat flour tortillas over whole wheat flour tortillas has been reported previously (Barros et al., 2010). However, oat-whole wheat flour tortillas was not evaluated previously. Wang et al. (2002) reported a good acceptance for bread with inuline but this acceptance was lower that we reported. Oat-whole wheat tortillas showed higher acceptance that whole wheat tortillas (Table 4). This product have not yet higher acceptability that whole wheat tortillas, but also showed the highest soluble dietary fiber concentration and lowest crude fat (Table 2).

\section{Conclusion}

Hot-press tortilla with oatmeal and inuline is an excellent way to improve dietary fiber consumption. $30 \%$ wheat flour substitution by oatmeal and $10 \%$ vegetable shortening substitution by inuline in a hot-press wheat tortilla generated a product with similar diameter, luminosity and yellowness but more redness. Texture parameters were not different until 5 days. Oatmeal-inuline tortilla had 30\% less crude fat, $15 \%$ more soluble dietary fiber and twice insoluble dietary fiber compared to typical wheat tortillas. This product is an excellent functional alternative to regular wheat tortillas because they provide higher nutritional value maintaining the same physical characteristics with high sensory acceptance.

\section{References}

AACC International. (2000). Approved Methods of the American Association of Cereal Chemists (10th Ed.). The Association: St. Paul, MN.

Alviola, J. N., \& Awika, J. M. (2010). Relationship between objective and subjective wheat flour tortilla quality evaluation methods. Cereal Chemistry, 87, 481-485. http://dx.doi.org/10.1094/CCHEM-03-10-0050

Anton, A. A., Ross, K. A., Lukow, O. M., Fulcher, R. G., \& Arntfiel, S. D. (2008). Influence of added bean flour (Phaseolus vulgaris L.) on some physical and nutritional properties of wheat flour tortillas. Food Chemistry, 109, 33-41. http://dx.doi.org/10.1016/j.foodchem.2007.12.005 
Barros, F., Alviola, J. N., \& Rooney, L. W. (2010). Comparison of quality of refined and whole wheat tortillas. Journal of Cereal Science, 51, 50-56. http://dx.doi.org/10.1016/j.jcs.2009.10.001

Dreher, M. L. (2001). Dietary fiber overview. In B. V. McCleary \& L. Prosky (Eds.), Dietary Fibre Technology Advanced (pp. 1-16), Blackwell Science, Oxford, UK.

Friend, C. P., Serna-Saldívar, S. O., Waniska, R. D., \& Rooney, L. W. (1992). Increasing the fiber content of wheat tortilla. Cereal Food World, 37, 325-328.

Madrigal, L., \& Sangronis, E. (2007). Inulin and derivatives as key ingredients in functional foods. Archivos Latinoamericanos de Nutricion, 57, 387-396.

O'brien, C. M., Mueller, A., Scannell, A. G. M., \& Arendt, E. K. (2003). Evaluation of the effects of fat replacers on the quality of wheat bread. Journal of Food Engineering, 56, 265-267. http://dx.doi.org/10.1016/S0260-8774(02)00266-2

Peressini, D., \& Sensidoni, A. (2009). Effect of soluble dietary fibre addition on rheological and breadmaking properties of wheat dough. Journal of Cereal Science, 49, 190-201. http://dx.doi.org/10.1016/j.jcs.2008.09.007

Posner, E. S., Chew-Guevara, A. A., Mitre-Dieste, M., Pérez-Carrillo, E., Heredia-Olea, E., Wilson, J. F., \& Serna-Saldívar, S. O. (2014). Generation of a Mixolab profile after the evaluation of the functionality of different commercial wheat flours for hot-press tortilla production. Cereal Chemistry, 91, 2-13. http://dx.doi.org/10.1094/CCHEM-05-13-0102-R

Prasopsunwattana, N., Botero Omary, M., Arndt, E. A., Cooke, P. H., Flores, R. A., Yokoyama, W., ... Lee, S. P. (2009). Particle size effects on the quality of flour tortillas enriched with whole grain waxy barley. Cereal Chemistry, 86, 439-451. http://dx.doi.org/10.1094/CCHEM-86-4-0439

Scazzina, F., Siebenhandl-Ehn, S., \& Pellegrini, N. (2013). The effect of dietary fibre on reducing the glycaemic index of bread. British Journal of Nutrition, 109, 1163-1174. http://dx.doi.org/10.1017/S0007114513000032

Seetharaman, L., McDonough, C. M., Waniska, R. D., \& Rooney, L. W. (2007). Microstructure of wheat flour tortillas: effects of soluble and insoluble fibres. Food Science Technology International, 3, 181-188. http://dx.doi.org/10.1177/108201329700300305

Serna Saldivar, S. O. (2012). Production of chemical-leavened products: crackers, cookies, cakes and related products, donuts and wheat flour tortillas. In Cereal Grains: Laboratory Reference and Procedures Manual (Chapter 10, pp. 279-285). CRC Press (Taylor \& Francis Group). Boca Raton, FL.

Wang, J., Rosell, C., \& Benedito-De Barber, C. (2002). Effect of the addition of different fibres on wheat dough performance and bread quality. Food Chemistry, 79, 221-226. http://dx.doi.org/10.1016/S0308-8146(02)00135-8

Yu, K., Ke, M. -Y., Li, W. -H., Zhang, S. -Q., \& Fang, X. -C. (2014). The impact of soluble dietary fibre on gastric emptying, postprandial blood glucose and insulin in patients with type 2 Diabetes. Asian Pacific Journal of Clinical Nutrition, 23, 210-8.

Zhao, D., Mulvaney, S., Chinnaswamy, R., Rayas-Duarte, P., Allvin, B., \& Wang, M. (2010). Elastics properties of gluten representing different wheat classes. Journal of Cereal Science, 52, 432-437. http://dx.doi.org/10.1016/j.jcs.2010.07.007

\section{Copyrights}

Copyright for this article is retained by the author(s), with first publication rights granted to the journal.

This is an open-access article distributed under the terms and conditions of the Creative Commons Attribution license (http://creativecommons.org/licenses/by/3.0/). 